\title{
Gestão estratégica de pessoas como fonte de vantagens competitivas nas organizações
}

\author{
Strategic management of people as a source of \\ competitive advantages in organizations
}

Samarina de Araújo Fragoso

Especialista em Gestão com Pessoas pelo Centro Universitário do Pará (Cesupa), professora do curso de Administração - Área de Ciências Sociais Aplicadas do Programa de Graduação em Administração do Centro Universitário do Pará (Cesupa), Belém, PA - Brasil, e-mail: spd27@hotmail.com

\section{Resumo}

Com o processo de globalização, ocorreram inúmeras transformações no cenário das empresas, provocando mudanças significantes, especificamente em relação à concorrência e à busca pela competitividade. Dessa forma, este artigo tem como propósito analisar ideias, conceitos e perspectivas acerca da gestão estratégica de pessoas como fonte de vantagem competitiva, a partir de um debate teórico fundamentado na visão dos autores, utilizando-se exemplos práticos de gestão. As categorias de discussão elencadas são: capital humano, modelos de gestão e mudanças. A metodologia utilizada está baseada em uma análise bibliográfica. A discussão sugere um aporte teórico pautado em uma gestão humanizada. Este artigo está dividido em quatro etapas: a primeira refere-se a uma abordagem sobre gestão estratégica e competitividade; a segunda etapa retrata o capital humano versus capital social organizacional; a terceira etapa discute os novos modelos de gestão; e a última etapa elucida os novos rumos acerca da gestão estratégica de pessoas. Os aspectos referentes à discussão refletem uma visão ampliada e conduzida no sentido da adoção de modelos mais adequados à gestão atual, sobretudo uma gestão mais humanizada.

Palavras-chave: Pessoas. Competitividade. Estratégias. Novos modelos de gestão. 


\begin{abstract}
As the globalization process, many changes occurred in the companies' scenario, causing significant changes, particularly in some aspects related to competition and the search for competitiveness. Therefore, this article aims to analyze ideas, concepts and perspectives about the strategic management of people as a source of competitive advantage, from a theoretical debate, discussion based on the authors' view, using practical examples of management. The categories listed for discussion are: the human capital, management models and changes. The methodology is based on a literature review. The discussion suggests a theoretical framework ruled out by a humanized management. This article is divided in four stages: the first refers to an approach on strategic management and competitiveness, the second part portrays the human capital versus organizational capital, the third step discusses the new management models and the last elucidates on the new directions about the strategic management of people. The issues relating to discussion reflect a broader view and driven towards the adoption of more appropriate models for the current administration, especially a more humanized management.
\end{abstract}

Keywords: Person. Competitiveness. Strategies. New models of management.

\section{Introdução}

O contexto atual da gestão de pessoas caracteriza-se pela capacidade de inovar em ações que garantam sustentabilidade às organizações diante da competitividade e novas estratégias mercadológicas. Por esse motivo, torna-se essencial a correta utilização dos meios de que dispõem as organizações para manter essa estabilidade competitiva e, sobretudo, a forma como cada uma delas planeja tal utilização, o que certamente as direciona para o sucesso ou fracasso. Preparar as equipes para a sustentabilidade requer um incremento em ações que possam transcender o ambiente organizacional e que, consequentemente, difere do que a maioria das empresas já faz.

Diante da acirrada concorrência, os fatores como tecnologia, informação, recursos financeiros, entre outros, não são mais os responsáveis pela garantia de sucesso das organizações, pois são facilmente adquiríveis por outras organizações e são pouco eficazes na contribuição para a sustentabilidade ao serem materializados como comuns. É necessário criar um ambiente de recursos genuinamente particulares e que sejam mais difíceis de copiar, o que, segundo Hanashiro, Teixeira e Zaccarelli (2008, p. 9), é necessário “reunir recursos menos comercializáveis, desenvolver recursos intangíveis, visando criar competências intrínsecas a cada organização, menos passíveis de imitação".

$\mathrm{Na}$ medida em que a competição é cada vez mais acirrada, tornar o igual diferente é uma questão de sobrevivência para as organizações e, sobretudo, um desafio, exigindo que as empresas tenham uma visão sistêmica do processo organizacional, especialmente sobre as pessoas. Cabe às organizações resguardar suas equipes, motivando-os e fazendo-os cooperar com resultados e comprometimento. $\mathrm{Na}$ discussão acerca dos fatores que alicerçam o gerenciamento dessas pessoas, faz-se necessária a utilização racional das competências organizacionais e pessoais, que se esforçam para gerar resultados que levam ao bom desempenho organizacional, aliada ao desempenho pessoal.

Embora muito se fale em gestão de pessoas, ainda há muitos questionamentos sobre as relações entre organizações e pessoas, o que se reforça na discussão sobre como a gestão estratégica de pessoas pode ser atrativa e assegurar a competitividade.

O contexto atual exige pessoas mais preparadas, com competências essenciais para enfrentar o mercado e, obviamente, também exige empresas dispostas a oferecer condições favoráveis ao desenvolvimento de competências.

A diferença entre as organizações atuais consiste no entendimento da essência humanística, "as pessoas", seus talentos, seus intelectos e conhecimentos, que agregam valores para as organizações, sendo esse o diferencial efetivo de competitividade entre as empresas.

\section{Suporte teórico-empírico}

\section{Gestão estratégica e competitividade}

O entendimento sobre a competitividade é algo antigo e, ao contrário do que a maioria pensa, já era praticado e discutido desde os tempos das leis 
da evolução de Charles Darwin, quando as espécies lutavam pela sobrevivência e competiam por alimentos e espaços. Sobre esse aspecto Henderson (1989 apud PORTER, 1998, p. 3) ressalta que "a competição existiu muito antes da estratégia. [...] os primeiros organismos unicelulares requeriam certos recursos para se manterem vivos. Quando os recursos eram adequados, o número de organismos aumentava de uma geração para outra". Ao compararmos a lei da sobrevivência à competição das organizações, percebe-se que "ao longo de milhões de anos desenvolveu-se uma complexa rede de interação competitiva", conforme afirma Henderson (1989 apud PORTER, 1998, p. 3). É preciso perceber que quanto mais variado for o ambiente maior será o número de variáveis potenciais que proporcionam condições únicas de vantagem.

Nesse processo de evolução, a demarcação diferencial é reconhecida por Henderson (1989 apud PORTER, 1998) considerando que os estrategistas usam a imaginação e capacidade de raciocínio lógico para incrementar a competição diante da velocidade das mudanças.

A necessidade de repensar suas estratégias e modelos fez com que as organizações refutassem as gestões engessadas, sem dimensões competitivas adequadas para o cenário contemporâneo. A perspectiva de gestão das empresas do século XXI é algo cada vez mais inovador, não há modelos prontos, como uma receita, com medidas previamente estabelecidas. A premente necessidade de evoluir de maneira eficaz fez com que a concepção sobre vários aspectos relacionados à gestão pudesse ir sendo substituída e modificada ao longo do tempo.

Para se compreender a gestão estratégica é necessário elucidar os conceitos de vantagem competitiva, definida por Lacombe (2005, p. 359) como "uma vantagem sobre os concorrentes, oferecendo mais valor para os clientes por meio de algo que o mercado valorize e os concorrentes tenham dificuldade em imitar". Porquanto, a competitividade não está configurada apenas no valor agregado a preços. O que pode assegurar essa competitividade é seguramente a capacidade de agregar valor e sustentá-lo a longo prazo. Para Hanashiro, Teixeira, Zaccarelli (2008, p. 9), "a competitividade reflete-se na posição relativa de uma empresa perante seus concorrentes, devendo possuir fontes de vantagem competitiva que resultem em atratividade de clientes superior aos seus concorrentes".
A estratégia, portanto, baseia-se na composição de ações que os gerentes/administradores utilizam para atrair clientes, fidelizar colaboradores e alcançar o desempenho organizacional ao nível de competitividade (HANASHIRO; TEIXEIRA; ZACCARELLI, 2008).

O conceito de estratégia (HENDERSON, 1989 apud PORTER, 1998, p. 5) é definido como sendo "a busca deliberada de um plano de ação para desenvolver e ajustar a vantagem competitiva de uma empresa", o que significa que a empresa necessita reconhecer quem é, de que recursos dispõe e onde pretende chegar. Os concorrentes que mais oferecem perigo são os que estão mais próximos em termos de vantagens competitivas (PORTER, 1998). Entretanto, as diferenças podem tornar-se relevantes quando se enxerga que, por menor e mais sutis que elas sejam, serão competitivas e demarcam essa diferenciação.

Certamente, para que empresas concorram e se intitulem competitivas entre si, elas devem ser altamente capazes de inovar em seus processos internos e ter a capacidade de buscar alternativas para se manter no mercado. Henderson (1989 apud PORTER, 1998, p. 7) classifica os elementos básicos da competição estratégica de tal maneira:

1) Capacidade de compreender o comportamento competitivo como um sistema no qual competidores, clientes, dinheiro, pessoas e recursos interagem continuamente;

2) Capacidade de usar essa compreensão para predizer como um dado movimento estratégico vai alterar o equilíbrio competitivo;

3) Recursos que possam ser permanentemente investidos em novos usos mesmo se os benefícios conseqüentes só aparecerem a longo prazo;

4) Capacidade de prever riscos e lucros com exatidão e certeza suficientes para justificar o investimento correspondente;

5) Disposição para agir.

Tais elementos tornam a essência da competição uma tarefa da qual requer comprometimento e dedicação, envolvendo todos da organização, caso contrário todo esforço se perderá em meio à incapacidade de atuar. Henderson (1989 apud PORTER, 1998) afirma ainda que esse compromisso estratégico se configura em um processo estudado, 
preparado, pensado, cujas consequências podem ser bruscas e em um espaço de tempo reduzido, sendo, portanto, a estratégia caracterizada pelo autor como revolucionária, o que fatalmente propõe mudanças no contexto organizacional em busca de melhores posições no mercado.

No tocante a essa questão, duas possibilidades são extraídas desse processo: uma é o fracasso, dado a incompetência de organizar os recursos disponíveis; a outra é o sucesso, concebido pela condução adequada dos recursos e pleno aproveitamento de capacidade humana, fator que não pode ser esquecido no processo de decisões estratégicas.

Uma questão fruto dessas duas perspectivas é a prioridade com que discute os "recursos mortos" e as pessoas. Se uma organização entende e prioriza as pessoas como sendo seu bem mais valioso, então ela entende também que necessita preparar esse ambiente para tal filosofia. Cercar-se de meios eficazes para alcançar vantagens mercadológicas não é um fator de garantia de sucesso. É, sobretudo, necessário evidenciar o que cada pessoa tem de melhor, seu potencial intelectual e sua capacidade de entrega, em que (DUTRA, 2001, p. 27) diz que corresponde à “agregação de valor dos indivíduos, é, portanto, sua contribuição efetiva ao patrimônio de conhecimentos da organização, o que lhe permite manter suas vantagens competitivas ao longo do tempo".

Esse é o ponto de partida para o entendimento entre a gestão e as pessoas, uma questão de adequação de construtos capazes de ampliar e modificar o pensamento sobre o ser humano no contexto organizacional.

\section{Capital humano versus capital social organizacional}

A capacidade de tornar os ativos estratégicos únicos não se resume em uma ação simplória ou de caráter universal. O contexto organizacional caracteriza-se por uma complexidade explícita por sua própria dinamicidade de atuação mercadológica. Essa condição exige das organizações a necessidade de se adquirir uma habilidade de aprendizado, aprimorada ao longo do tempo (REED; DEFILLIPI, 1990 apud HANASHIRO; TEIXEIRA;ZACCARELLI, 2008).

A base de toda relação em uma organização é cerceada pelas contribuições individuais somadas à organização propriamente dita, de tal forma que essa soma possa ser refletida entre as pessoas, por meio de visões compartilhadas. Dessa forma, o capital social é definido:

como um recurso que reflete o caráter das relações sociais existentes na organização, decorrente da orientação coletiva para alcançar os resultados e a confiança compartilhada por seus membros, facilitando o aprendizado coletivo (LEANA; BUREN 1999 apud HANASHIRO; TEIXEIRA; ZACCARELLI, 2008, p. 12).

Dessa maneira, o capital social da organização associado ao capital humano compõe o capital organizacional. O capital humano é refletido por habilidades, competências, conhecimentos, criatividade, inovação, intelecto dos colaboradores da organização. Por sua vez, o capital organizacional está ligado à cultura, aos sistemas organizacionais, aos direitos de propriedade intelectual, entre outros (HANASHIRO; TEIXEIRA; ZACCARELLI, 2008).

A troca de informação entre esses fatores se constitui nas relações de confiança que precisam ser vivenciadas para consolidar a base do aprendizado coletivo. A partir dessa visão, pode-se considerar o capital social organizacional responsável pela vantagem competitiva como ativo estratégico, somado ao capital organizacional e ao capital humano.

E necessário muito mais que concatenar ideias e organizar estratégias para se alcançar o sucesso. A correta execução e o aproveitamento do capital humano e capital social organizacional são consequências de uma visão ampliada sobre a concepção de pessoas. Pensamentos contemporâneos convergem cada vez para o gerenciamento humanizado no sentido de alcançar a eficiência e eficácia organizacional.

A avaliação constante do capital humano possibilita uma maior congruência de valores da organização e de seus funcionários, ressaltando as competências, habilidades, experiências e grau de comprometimento com suas atribuições e para com a organização.

Essa combinação de avaliação e estratégias de reconhecimento contribui para um desempenho (estruturado), conforme ressalta Lacombe (2005, p. 353): "os esforços individuais continuam sendo necessários e desejáveis, mas o mais importante é a contribuição aos resultados da equipe". Porquanto, as equipes de trabalho necessitam ser "exploradas" em suas potencialidades, considerando que a capacidade de participação e contribuição humana são 


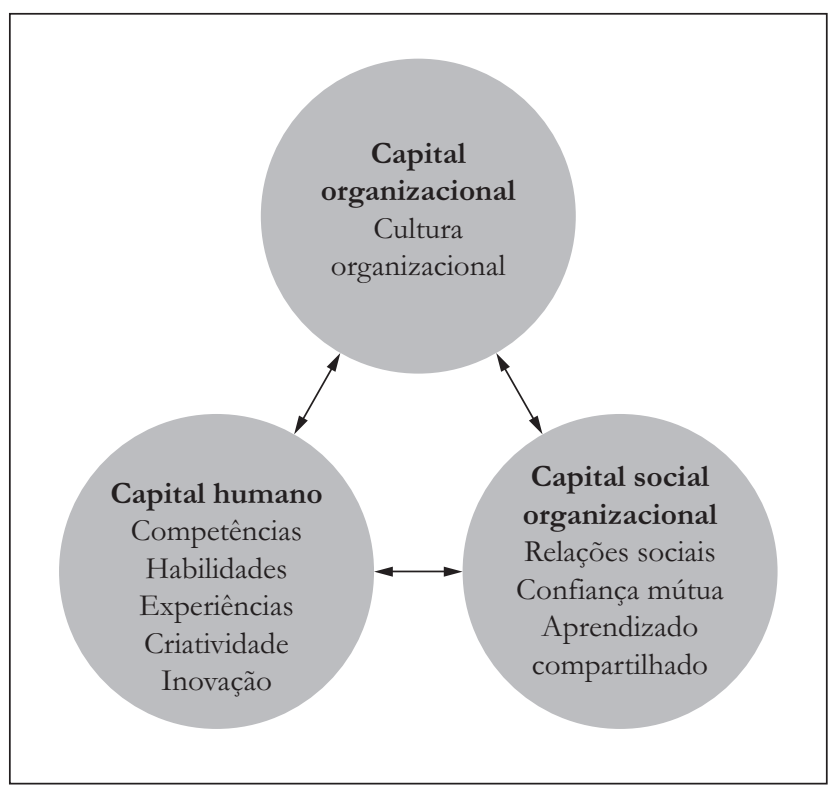

Figura 1 - Relação entre capital humano, social e organizacional

Fonte: Adaptado de HANASHIRO; TEIXEIRA; ZACCARELLI, 2008, p. 12.

maiores quando a empresa estimula ao máximo essa capacidade de buscar soluções, desencadeando o processo espontâneo de criatividade.

Portanto, cuidar do patrimônio humano é cuidar da longevidade e sustentabilidade da organização, prospectando novas possibilidades de crescimento, utilizando para isso a capacidade humana de contribuir, de criar, inovar e competir estrategicamente.

\section{Novos modelos de gestão}

O novo cenário de desestabilização do mercado apresenta como consequência a oportunidade das empresas adotarem um novo modelo de gestão de pessoas, desafiando-as a tornarem-se mais produtivas, comprometidas, envolvidas e motivadas para o trabalho. Essa perspectiva do mundo atual implica aos gestores a eminente mudança da uma visão microscópica ${ }^{1}$ do homem sob a óptica da abordagem clássica para uma visão sistêmica, ${ }^{2}$ pensando as pessoas como fator primordial para se manter no mercado. Essa visão de homem torna-se necessária à medida que há o discernimento do "ser" como um ser social, pensante, agente transformador e responsável pelo sucesso das organizações. Essa mudança de visão também recai sobre as "pessoas" por meio de um movimento inverso, sobretudo quando estas resistem às mudanças, especialmente as de ordem interna. Esse movimento implica tornar esse homem parte de um todo, parte essa considerada a mais importante no contexto em que se insere. Para Minicucci (2001), as pessoas resistem às mudanças, especialmente se elas forem impostas. Surge então a complexa tarefa de promover estímulos ao trabalho, levando em consideração a propensão à resiliencia ${ }^{3}$ e suas condições humanas.

Os novos modelos de gestão apresentam-se como formas de atuar diante das diversas influências sofridas na dinâmica das organizações. França (2009, p. 18) fala sobre o "modelo participativo de gestão onde ' $[. .$.$] predominam a liderança, a disciplina e a$ autonomia'. Nas organizações que adotam o modelo participativo, as pessoas são responsáveis por seu próprio comportamento e desempenho". A adoção desse modelo é proporcional ao poder de decisão (autonomia) e ao senso de responsabilidade que cada indivíduo assume na organização.

Entretanto, os modelos adotados pela maioria das empresas nem sempre se apresentam como modelos predominantemente participativos. Em alguns casos, as empresas adotam modelos mais ou menos diretivos e mais ou menos participativos, atuando conjuntamente (FRANÇA, 2009). É importante ratificar que as empresas modernas deverão cada vez mais acompanhar as tendências dos modelos de gestão, os quais são mais humanizados e participativos

1 “A Administração Científica refere-se à pessoa como um empregado considerado individualmente, ignorando que ela é um ser humano e social (CHIAVENATO, 2001, p. 79).

2 "A solução de problemas atualmente exige um amplo enfoque para um sistema, mais do que a obsessão de aprofundamento do problema particular em questão. Isto significa olhar o problema sob uma perspectiva mais ampla, ou seja, sob o ponto de vista de sistemas, um ponto de vista holístico" (SILVA, 2004, p. 350).

3 "É a capacidade do sistema de superar o distúrbio imposto por um fenômeno externo. As organizações, como sistemas abertos, apresentam capacidade de enfrentar e superar perturbações externas provocadas pela sociedade sem que desapareça seu potencial de auto-organização" (CHIAVENATO, 2002, p. 349). 
substituindo aos poucos os modelos tradicionais e obsoletos.

A mudança no aspecto mercadológico propõe uma discussão trilhada nos entraves da gestão de pessoas, reflexões e decisões pautadas nas mudanças estratégicas demandadas pelo mercado competitivo com caráter volátil e adaptativo.

Saber usufruir dos talentos humanos com sabedoria é aliar as ações concretas de conquistar, reter, aplicar e desenvolver talentos e acima de tudo gerir as competências para o alcance dos resultados. Segundo Lacombe (2005, p. 370), “a empresa deve procurar desenvolver em seu pessoal múltiplas habilidades que facilitem seu aproveitamento em diferentes posições".

A competição acirrada introduz, no cenário das organizações, aspectos que exigem dos gestores ações mais efetivas no que concerne ao atendimento das exigências mercadológicas, propondo, enfim, uma reestruturação e renovação diária que necessita acompanhar o ritmo dinâmico das empresas, imprimindo novos conceitos, transformações rápidas e tomadas de decisões mais assertivas para o mercado. Eis que surge a partir dessa perspectiva, a discussão de que a mudança torna-se nula quando não há uma mudança de cultura organizacional, ${ }^{4}$ o que seguramente compromete o pensar estrategicamente a organização por meio da mudança planejada.

Tornar as organizações competitivas, tomando como foco sua dimensão humana, é acima de tudo um desafio para os gestores e gera a reflexão da mudança de conceito sobre as pessoas na organização. Porquanto, é fundamental refletir: afinal o que as pessoas representam para as empresas? Seriam elas apenas "recursos" ou seriam pessoas fundamentais na construção de empresas melhores e mais humanas?

As empresas que já conseguiram compreender a nova estrutura humana surgida em decorrência das mudanças mercadológicas pensam o fator (pessoas) como estratégico e de fundamental importância nos processos decisórios, na busca do questionamento de como as empresas podem ser altamente competitivas utilizando as pessoas como fator determinante para isso?

A exemplo, a empresa Google, que adota práticas inovadoras de atuação em sua gestão de pessoas. A empresa utiliza-se da prática do "bem-estar" dentro da organização e aposta na qualidade de vida dos funcionários, tornando o ambiente de trabalho um lugar agradável, descontraído, sem formalidades, o que proporciona a mistura do lúdico com o real mundo corporativo. A Google adotou propostas inovadoras que vão do meio de locomoção dentro do espaço organizacional até salas de descanso, como:

- um tobogã que liga os escritórios do primeiro piso à cafeteria e um ginásio;

- a empresa ganha um ar familiar quando um espaço foi pensado para os filhos dos funcionários, que podem divertir-se em um ginásio;

- três refeições diárias são servidas no restaurante da empresa;

- locais para descanso em cada andar;

- os funcionários fazem seus horários de trabalho;

- salas de massagem e muitos outros benefícios existentes nesse ambiente que mais parece um hotel de férias que uma empresa.

Com essas estratégias, a Google auferiu o título de melhor empresa para se trabalhar. O fator "felicidade" no trabalho faz toda a diferença quando se espera contar com profissionais capazes de dar o melhor de si em prol da organização. Todo o esforço para se alcançar os objetivos da organização acaba sendo algo natural e prazeroso, pois ficar em um ambiente como o da empresa Google é como estar em casa. A identidade de incorporação dos indivíduos, como parte do todo da empresa, faz com que os funcionários sintam-se inseridos, valorizados e felizes.

A proposta da empresa reitera a ideia de que organizações “inteligentes” são organizações humanas, que de fato preocupam-se com as pessoas e, consequentemente, alcançam o sucesso por considerarem o potencial humano como seu bem mais valioso.

Ao que parece a palavra de ordem é ter flexibilidade nos modelos de gestão, garantindo uma atuação mais participativa, fazendo dessas organizações as mais preparadas para atuar nos ambientes corporativos complexos que se encontram as organizações atuais. 4 "É o sistema de valores, crenças, normas e hábitos compartilhados, que rege a interação dos elementos de uma organização"
(SILVA, 2004, p. 421). 


\section{As mudanças e os novos rumos na gestão estratégica}

Ao que parece, esse novo milênio promete muitas e inesperadas surpresas com relação ao mundo empresarial. Muitas dessas surpresas fatalmente serão modismos subsequentes apostados em tendências mundiais, mas o efeito e o resultado de tudo isso é que ainda é uma incógnita. Ao certo, não se tem como prever o que nos espera em termos de gestão, mas já sabemos que modelos engessados, gestão centralizadora e altamente hierarquizada e políticas internas fracas são variantes organizacionais com tendência à extinção.

A gestão tende a se ampliar cada vez que a concorrência, a modernidade, a tecnologia, os avanços em ciências também se ampliam. A necessidade premente de mudança conduz as empresas ao aprimoramento de técnicas e de modelos que se enquadrem mais perfeitamente ao mercado atual (exigente, turbulento, surpreendente). O aprimoramento é a busca de modelos que acompanham as mudanças, dando à gestão uma "cara" de gestão verdadeiramente estratégica, para se atuar em mercados como os atuais.

De fato, muitas empresas já caminham em direção a um movimento para a visão de gestão estratégica, valorizando as pessoas e vendo os resultados como frutos de uma visão compartilhada por toda a organização. Essa é a visão do futuro para as empresas que buscam estabilidade, longevidade e sustentabilidade no mercado. Segundo Hamel (2010, p. 49), "se pretendem vencer no futuro, as organizações têm de encontrar maneiras de energizar as pessoas, para que não apliquem nos trabalhos apenas capacidades, mas também sua paixão e iniciativa".
Em um futuro muito próximo, o talento humano será capaz de transformar pequenas ações em grandes feitos, em função do intelecto e da capacidade de atuar em ambientes inovadores e com atos potenciais para a criatividade.

As organizações devem adotar medidas que as permitam se reinventar (renovar) dia após dia no novo cenário organizacional. E, mais que isso, ter a capacidade de esquecer os fracassos e cultivar a cultura da renovação e criatividade. As organizações atuais necessitam semear conhecimento a partir do entendimento da visão sistêmica compartilhada na organização.

Portanto, ao se pensar em gestão estratégica é preciso pensar em criatividade, inovação, tecnologia, unindo arte, desafio e sentido humano para as realizações. Sem dúvida, este é o desafio do futuro: tornar as organizações mais humanas e substancialmente competitivas por tal razão.

\section{Metodologia}

Trata-se de uma pesquisa básica quanto à sua natureza, descritiva quanto ao seu objetivo; qualitativa quanto à abordagem do problema; e bibliográfica quanto aos procedimentos técnicos, com interesse em debate teórico sobre a gestão estratégica de pessoas.

A abordagem metodológica consiste em revisitar autores, conforme quadro de referências (Quadro 1), a partir de um referencial teórico básico, utilizando-se da análise de conteúdo para identificar percepções dos autores que apontam para as perspectivas atuais acerca da gestão estratégica de pessoas como fonte de vantagem competitiva.

\begin{tabular}{ll}
\hline Abordagens & Autores \\
\hline Competição e competitividade & PORTER, 1998. \\
Competição & HENDERSON apud PORTER, 1998. \\
Competitividade e estratégias & HANASHIRO; TEIXEIRA; ZACCARELLI, 2008. \\
Ser humano e vantagens competitivas & DUTRA, 2001. \\
Pessoas e capital social & REED; DEFILLIPI apud HANASHIRO; TEIXEIRA; ZACCARELLI, 2008. \\
& LEANA; BUREN apud HANASHIRO, TEIXEIRA; ZACCARELLI, 2008. \\
Mudanças & MINICUCCI, 2001.
\end{tabular}

Quadro 1 - Abordagens teóricas

(Continua) 


\begin{tabular}{ll}
\hline Abordagens & Autores \\
\hline Reconhecimento de potencial humano & LACOMBE, 2005. \\
Modelos participativos & FRANÇA, 2009. \\
Valor humano & HAMEL, 2010. \\
Teoria do crescimento da firma & RUGMAN; ALAN; VERBEKE, ALAIN; KOR; MAHONEY. \\
\hline
\end{tabular}

Quadro 1 - Abordagens teóricas

(Continua)

\section{Resultados}

O fator revelador, a partir da revisão da bibliografia sobre o assunto em questão, norteia a postura com relação à gestão de pessoas para as próximas décadas, no tocante aos novos modelos de gestão que devem ser incorporados às tendências atuais como forma de obter vantagens competitivas.

Segundo os autores, inegavelmente as empresas terão que mudar suas concepções de modelos se desejarem perdurar no mercado. $\mathrm{O}$ fenômeno da competição acirrada tenderá a crescer vertiginosamente nas próximas décadas, exigindo atenção por parte dos gestores.

Ao perceber o ser humano como fator de vantagem competitiva, é necessário antes perceber seu lado humano, sua forma de participação e contribuição para as organizações atuais. É preciso pensar essa fonte de vantagem competitiva como uma herança intelectual geradora de inovação e competências associadas à criação de valor.

\section{Conclusões}

Este artigo não pretendia responder aos questionamentos que cerceiam a gestão estratégica de pessoas, mas buscava a compreensão e o posicionamento dos autores acerca dela, assim como analisar as ideias, os conceitos e as perspectivas, incitando a discussão sobre as concepções das organizações mais humanas, sendo também competitivas.

Hanashiro, Teixeira e Zaccarelli (2008) relacionam a gestão estratégica de pessoas reconhecendo a diferenciação entre as empresas a partir da essência humana, sendo considerados fatores difíceis de ser copiados por conta da competência, do conhecimento, do potencial humano, entre outros. Para Lacombe
(2005), o pensamento sobre a gestão estratégica de pessoas é visto como vantagem quando cria valor para a organização a partir dos seus clientes, apontando também para o desenvolvimento de múltiplas habilidades que se tornam essenciais na competição entre mercados.

Em seus estudos sobre a teoria do crescimento da empresa (PENROSE, 1959 apud KOR; MAHONEY, 2004) pontua sobre a criação de vantagens competitivas, sobretudo de uma administração efetiva dos recursos, que as organizações dispõem. Recursos esses que podem gerar oportunidades criativas e estratégias de diversificação da empresa. Esses autores pontuam ainda que a autora elenca três aspectos considerados relevantes, sendo estes: os recursos da organização, as capacidades e a competitividade. Tais recursos são capazes de gerar lucro para as empresas (rentabilidade). Entretanto, a autora ressalta que a empresa pode criar valores econômicos a partir da utilização inovadora e efetiva dos recursos, adequando-os às demandas mercadológicas.

Segundo Penrose (1959 apud KOR; MAHONEY, 2004) elucida o caráter idiossincrático de cada organização acerca de seus recursos. A característica de heterogeneidade das empresas é transformada em desdobramentos criativos que geram oportunidades criativas, tornando-se diferenciais competitivos efetivos. Ainda sobre as concepções da autora, há uma relação de causa e consequência entre os recursos e a geração de oportunidades produtivas para o crescimento e a inovação da empresa, desde que esta consiga utilizar de maneira adequada os seus recursos. A autora reconhece que o nível de performance da empresa está associado ao número de recursos que ela dispõe, assim como a importância da manutenção desses recursos, fatores determinantes no crescimento e expansão da empresa.

Nos estudos de Penrose (1959), é importante ressaltar que seus estudos corroboram com as 
teorias que sustentam a competitividade e que se unem na construção de recursos efetivos e essencialmente diversificadores e inovadores. O tema em questão acirra o debate como construto de ideias provocativas no sentido de discussão e busca de soluções para o alcance da competitividade a partir das pessoas.

Com o estudo, é reveladora a necessidade de incentivo a pesquisas na área e, sobretudo, solidificar a ideia do homem como ser construto, ser relacional, ser emotivo, ser participativo, ser criativo, ser inovador, ser bumano. Essa visão renovada do homem é que vai direcionar a gestão estratégica, garantindo a competitividade. No tocante a essa questão, gestores e funcionários necessitam de uma renovação continuada das competências, organizacionais e individuais.

\section{Referências}

CHIAVENATO, I. Teoria geral da administração. 6. ed. Rio de Janeiro: Elsevier, 2001.

CHIAVENATO, I. Teoria geral da administração. 6. ed. Rio de Janeiro: Elsevier, 2002.

DUTRA, J. S. (Org.). Gestão por competências: um modelo avançado para o gerenciamento de pessoas. 3. ed. São Paulo: Gente, 2001.

FRANÇA, A. C. L. Práticas de Recursos Humanos PRH: conceitos, ferramentas e procedimentos. 2. ed. São Paulo: Atlas, 2009.

HANASHIRO, D. M. M. et al. Gestão do fator humano: uma visão baseada em stakeholders. 2. ed. São Paulo: Saraiva, 2008.

HAMEL, G. Gestão na era da criatividade. Revista HSM Management, São Paulo, v. 8, n. 79, p. 47-53, 2010.

KOR, Y. Y.; MAHONEY, J. T. Edith Penrose's (1959) Contributions to the Resource-based View of Strategic Management. Journal of Management Studies, v. 1, n. 41, p. 181-193, jan. 2004.

LACOMBE, F. J. M. Recursos humanos: princípios e tendências. 2. ed. São Paulo: Saraiva, 2005.

MINICUCCI, A. Relações humanas: psicologia das relações interpessoais. 6. ed. São Paulo: Atlas, 2001.

PENROSE, E. T. The theory of the growth of the firm. 2nd ed. New York: John Wiley, 1959.
PORTER, M. Clusters and the new economics of competition. Harvard Business Review, London, v. 7, n. 6, p. 66-79, 1998.

SILVA, R. O. da. Teorias da administração. 2. ed. São Paulo: Pioneira Thomson Learning, 2004.

Recebido: 16/09/2010

Received: 09/16/2010

Aprovado: 25/11/2010

Approved: 11/25/2010 